\title{
Role of L- and D-Menthol in the Glucuronidation and Detoxification of the Major Lung Carcinogen, NNAL ${ }^{\mathbb{D}}$
}

\author{
[1] Shannon Kozlovich, (1) Gang Chen, Christy J.W. Watson, William J. Blot, and Philip Lazarus
}

Department of Pharmaceutical Sciences, College of Pharmacy and Pharmaceutical Sciences, Washington State University, Spokane, Washington (S.K., G.C., C.J.W.W., P.L.); and Division of Epidemiology, Vanderbilt University Medical Center, Nashville, Tennessee (W.J.B.)

Received June 14, 2019; accepted September 25, 2019

\begin{abstract}
Menthol, which creates mint flavor and scent, is often added to tobacco in both menthol and nonmenthol cigarettes. A potent tobacco carcinogen, 4-(methylnitrosamino)-1-(3-pyridyl)-1-butanone (NNK), is extensively metabolized to its equally carcinogenic metabolite 4-(methylnitrosamino)-1-(3-pyridyl)-1-butanol (NNAL) as $(R)$ - or (S)-NNAL enantiomers. NNAL is detoxified by UDPglucuronosyltransferase (UGT) enzymes, with glucuronidation occurring on either NNAL's pyridine ring nitrogen (NNAL-N-Gluc) or the chiral alcohol [(R)- or (S)-NNAL-O-Gluc]. To characterize a potential effect by menthol on NNAL glucuronidation, in vitro menthol glucuronidation assays and menthol inhibition of NNALGluc formation assays were performed. Additionally, NNAL and menthol glucuronides (MG) were measured in the urine of smokers ( $n=100)$ from the Southern Community Cohort Study. UGTs 1A9, 1A10, 2A1, 2A2, 2A3, 2B4, 2B7, and 2B17 all exhibited glucuronidating activity against both L- and D-menthol. In human liver microsomes, both L- and D-menthol inhibited the formation of each NNAL-Gluc, with a stereospecific difference observed between the formation of $(R)$ NNAL-O-Gluc and (S)-NNAL-O-Gluc in the presence of D-menthol but
\end{abstract}

not L-menthol. With the exception of three nonmenthol cigarette smokers, urinary MG was detected in all menthol and nonmenthol smokers, with L-MG comprising $>\mathbf{9 8} \%$ of total urinary MG. Levels of urinary NNAL-N-Gluc were significantly $(P<0.05)$ lower among subjects with high levels of total urinary MG; no significant changes in free NNAL were observed. These data suggest that the presence of menthol could lead to increases in alternative, activating metabolic pathways of NNAL in tobacco target tissues, increasing the opportunity for NNAL to damage DNA and lead to the development of tobacco-related cancers.

\section{SIGNIFICANCE STATEMENT}

High levels of the major menthol metabolite, menthol-glucuronide, was observed in the urine of smokers of either menthol or nonmenthol cigarettes. The fact that a significant inverse correlation was observed between the levels of urinary menthol-glucuronide and NNAL-Nglucuronide, a major detoxification metabolite of the tobacco carcinogen, NNK, suggests that menthol may inhibit clearance of this important tobacco carcinogen.

\section{Introduction}

Tobacco use is considered by the World Health Organization to be the leading cause of preventable premature death in adults worldwide (Saika and Machii, 2012). Tobacco-specific nitrosamines (TSNAs), including

These studies were funded in part by the National Institutes of Health, National Institutes of Environmental Health Sciences [Grant R01-ES025460] to P.L. and the Health Sciences and Services Authority of Spokane, Washington [Grant WSU002292] to Washington State University. The Southern Community Cohort Study was supported by the National Cancer Institute (Grants R01CA092447 and U01CA202979). Data collection was performed by the Survey and Biospecimen Shared Resource, which is supported in part by the Vanderbilt-Ingram Cancer Center (Grant P30 CA68485).

The data contained in this manuscript were presented in whole or part at the Experimental Biology (2019) and Society for Research on Nicotine and Tobacco (2019) conferences and as a chapter in the doctoral dissertation of Shannon Kozlovich.

https://doi.org/10.1124/dmd.119.088351

SThis article has supplemental material available at dmd.aspetjournals.org. (methylnitrosamino)-1-(3-pyridyl)-1-butanone (NNK), are among the most potent carcinogens found in both tobacco smoke and smokeless tobacco. NNK is rapidly metabolized in smokers by carbonyl reduction to both the $(R)$ - and $(S)$-enantiomers of the equally potent carcinogen, 4-(methylnitrosamino-1-(3-pyridyl)-1-butanol (NNAL) (Nemzek et al., 1998). The glucuronidation of NNAL by the UDP glucuronosyltransferase (UGT) family of enzymes is considered an important mechanism for NNK detoxification (Upadhyaya et al., 1999), forming an $O$-glucuronide $(O$-Gluc) on the alcohol within the NNAL side chain or an $\mathrm{N}$-glucuronide ( $\mathrm{N}$-Gluc) on the nitrogen of the NNAL pyridine ring. UGTs $1 \mathrm{~A} 9,1 \mathrm{~A} 10,2 \mathrm{~B} 7$, and $2 \mathrm{~B} 17$ have been shown to form NNAL-O-Gluc (Ren et al., 2000; Wiener et al., 2004a; Balliet et al., 2010; Chung et al., 2013; Gruber et al., 2013; Wassenaar et al., 2015), with UGTs $2 \mathrm{~B} 7$ and $2 \mathrm{~B} 17$ primarily responsible for the stereospecific formation of $(S)$-NNAL- $O$-Gluc and $(R)$-NNAL$O$-Gluc, respectively (Kozlovich et al., 2015). Although both UGTs $2 \mathrm{~B} 10$ and $1 \mathrm{~A} 4$ have been shown to form NNAL- $N$-Gluc in vitro (Wiener et al., 2004a,b; Chen et al., 2008b; Kozlovich et al., 2015), UGT2B 10 is responsible for $>90 \%$ of NNAL- $N$-Gluc formation in

ABBREVIATIONS: HEK293, human embryonic kidney cell line 293; HIM, human intestinal microsome; HLM, human liver microsome; IS, internal standard; LC-MS/MS, liquid chromatography tandem mass spectrometry; MG, menthol glucuronides; MS, mass spectrometry; NNAL, 4(methylnitrosamino)-1-(3-pyridyl)-1-butanone; NNK, 4-(methylnitrosamino)-1-(3-pyridyl)-1-butanol; QTOF, quadrupole time-of-flight; SCCS, Southern Community Cohort Study; TSNA, tobacco-specific nitrosamines; UGT, UDP-glucuronosyltransferase; UPLC, ultraperformance liquid chromatography. 
human liver microsomes (HLMs) and in the urine of smokers (Chen et al., 2008b, 2016; Murphy et al., 2018b).

Menthol is a flavor additive in many brands and types of tobacco products. It is listed by the Food and Drug Administration as "generally regarded as safe" but is regulated as a drug when it is the active ingredient in a medication and subsequently has required dosage labeling in these situations; however, when used as a flavor additive in tobacco products, there are no labeling requirements for the amount of menthol added Tobacco Products Scientific Advisory Committee, 2011) TPSA. Whereas a cohort study reported an increased risk of developing lung cancer for male menthol smokers compared with nonmenthol smokers (Sidney et al., 1995), other epidemiologic investigations have not found similar trends (Kabat and Hebert, 1991; Carpenter et al., 1999; Brooks et al., 2003; Stellman et al., 2003; Murray et al., 2007; Blot et al., 2011; Rostron, 2012; Munro et al., 2016). Indeed, epidemiology data from the entire Southern Community Cohort Study (SCCS), from which the urine samples in the present analysis were drawn, show a significantly lower tisk of lung cancer, by about $30 \%$, among menthol than among nonmenthol smokers for both black and white racial groups (Blot et al., 2011; Munro et al., 2016), and two meta-analyses likewise show lower rather than higher risks of lung cancer among menthol compared with nonmenthol smokers (Lee, 2011; Jones et al., 2013). With the presence of menthol in many edible and topical products in the United States, however, the presence of either L- or D-menthol metabolites in the urine of smokers could be from menthol sources other than tobacco. Previously, urinary menthol was not previously found to be associated directly with levels of dietary menthol (Benowitz et al., 2010) and potentially could arise from a complex mix of exposures from edible, topical, and tobacco products in both menthol and nonmenthol smokers. Since the underlying mechanism to determine menthol's impact for health risk in smokers is currently unknown, an understanding of the molecular basis of menthol clearance and the mechanism of inhibition within the clearance pathway of tobacco carcinogens may aid in understanding the health disparities for the racial groups with the highest rate of menthol cigarette use.

Menthol is a chiral aliphatic alcohol, existing as either the D- or L-menthol, and the racemic mixture is referred to as DL-menthol. The only naturally occurring enantiomer, the one found in and isolated from a variety of mint plant species, is L-menthol. The other enantiomer, D-menthol, is a product of the Haarmann \& Reimer (Holzminden, Germany) industrial synthesis process, which yields a DL-menthol mixture (Oertling et al., 2007). It has been long known that D-menthol does not produce the same smell and taste profile normally associated with naturally occurring menthol and that its analgesic properties are greatly reduced compared with L-menthol (Eccles et al., 1988; Bhatia et al., 2008; Lawrence et al., 2011). When menthol is the active ingredient in over-the-counter pharmaceuticals, such as lozenges, only the L-menthol enantiomer tends to be present (US FDA, 2018); however, the same may not be true for tobacco products (TPSAC, 2011). Studies have examined the total menthol content in both menthol and nonmenthol cigarettes, which can range from $1.0 \%$ to $0.3 \% \mathrm{wt} / \mathrm{wt}$ with as low as $1.5 \mathrm{mg}$ menthol per cigarette in menthol cigarettes (Celebucki et al., 2005) and up to $0.03 \% \mathrm{wt} / \mathrm{wt}$ with an upper level of $0.07 \mathrm{mg}$ menthol/cigarette in nonmenthol cigarettes (Giovino et al., 2004). Whereas DL-menthol has previously been identified as an inhibitor of both NNAL- $O$-Gluc and NNAL- $N$-Gluc production in HLMs (Muscat et al., 2009), no studies have been performed to determine which UGT enzymes are being inhibited or which menthol enantiomer is driving the inhibition.

The racial groups in the United States with the highest rate of menthol smokers, African Americans (Sidney et al., 1995) and Native Hawaiians (TPSAC, 2011), also have the highest rate of tobacco-related cancers among smokers (Coultas et al., 1994; Haiman et al., 2006; Daraei and Moore, 2015; Xie et al., 2017; Murphy et al., 2018a). Although African Americans smoke fewer cigarettes per day than smokers in other racial groups (Caraballo et al., 1998; Benowitz et al., 2009; Benowitz et al., 2011), they may be exposed to more toxins per cigarette (Clark et al., 1996; Perez-Stable et al., 1998). Native Hawaiians have a higher rate of tobacco-related DNA damage compared with white and Japanese Americans (Park et al., 2018). Genetic differences in the tobacco addiction pathway do not seem to account for the differences in cancer risk observed between these populations (Murphy et al., 2018a).

The underlying mechanism or interaction of menthol within the tobacco carcinogen pathway has yet to be fully elucidated. L-menthol exhibits inhibition of CYP2A6 and CYP2A13 carcinogen activation and nicotine metabolism (Kramlinger et al., 2012), but cytochrome P450s do not directly metabolize menthol. It is known that menthol is rapidly cleared from the body as a menthol glucuronide (MG) (Kaffenberger and Doyle, 1990; Gelal et al., 1999), the same clearance pathway as the TSNAs. Yet, no previous research has described the complete clearance pathway of menthol enantiomers. The goal of the present study was to identify the enzymes responsible for the metabolism of both L- and D-menthol to their respective glucuronides, as both could possibly be found in tobacco products (TPSAC, 2011), and to investigate the potential impact of each menthol enantiomer on NNAL glucuronide formation in vivo.

\section{Materials and Methods}

Chemicals and Materials. rac-NNAL (M325740), NNAL- $N$-Gluc (M325745), NNAL-O-Gluc (M325720), NNAL-13C 6 (M325741), L-MG

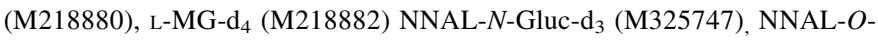
Gluc- $\mathrm{d}_{5}$ (M325722), creatinine (C781500), and creatinine- $\mathrm{d}_{3}$ (C781502) were purchased from Toronto Research Chemicals (Toronto, ON, Canada). L- and D-menthol (W266523, 224464), UDP glucuronic acid, alamethicin, methanol, and acetonitrile were purchased from Sigma (St. Louis, MO). Dulbecco's modified Eagle's medium, fetal bovine serum, geneticin, and penicillin-streptomycin were purchased from Life Technologies (Carlsbad, CA). The Pierce BCA protein assay kit, ammonium acetate, and formic acid were purchased from Fisher Scientific (Fair Lawn, NJ).

Subjects and Biospecimens. Urine and subject demographics were obtained from 100 self-identified current smokers upon recruitment into the SCCS, a prospective cohort of more than 84,000 participants recruited between 2002 and 2009 (Signorello et al., 2010). One-time spot urine samples $(\sim 60 \mathrm{ml})$ were collected from SCCS participants at community health centers beginning in 2004. Samples were refrigerated onsite and shipped overnight to Vanderbilt Medical Center, where urine was mixed with a small amount of ascorbic acid and stored at $-80^{\circ} \mathrm{C}$

Urine specimens $(150 \mu \mathrm{l}$ each) were randomly chosen from 50 menthol smokers and 50 nonmenthol smokers, and were received at Washington State University College of Pharmacy and Pharmaceutical Sciences for analysis by overnight shipment and subsequently stored at $-80^{\circ} \mathrm{C}$. Smoking preference for menthol cigarettes was self-identified at the time of urine sample collection. Subjects were $34 \%$ white, $60 \%$ black, $1 \%$ Hispanic, and 5\% mixed race, and comprised $56 \%$ women.

Pooled $(n=200)$ HLMs and pooled $(n=10)$ human intestinal microsomes (HIMs) were purchased from Xenotech (Lenexa, KS).

Cell Lines and Microsomal Preparation. Individual human embryonic kidney cell line 293 (HEK293) cell lines overexpressing 18 human UGTs (1A1, 1A3, 1A4, 1A5, 1A6, 1A7, 1A8, 1A9, 1A10, 2A1, 2A2, 2A3, 2B4, 2B7, 2B10, 2B11, 2B15, and 2B17) have been described previously (Ren et al., 2000; Dellinger et al., 2006; Sun et al., 2006). The parent HEK293 cell line used in this study was obtained before 2000 and was most recently authenticated by the American Type Culture Collection using short tandem repeat analysis in December 2017. The individual HEK293 UGT overexpressing cell lines were verified to contain the UGT clone of interest by Sanger sequencing in August 2016 by GeneWiz, LLC (South Plainfield, NJ). All HEK293 cell lines were grown in 150 -mm plates to $80 \%$ confluence in $30 \mathrm{ml}$ of Dulbecco's modified Eagle's medium supplemented with $10 \%$ fetal bovine serum and maintained in $400 \mu \mathrm{g} / \mathrm{ml}$ 
of geneticin in a humidified incubator atmosphere of $5 \% \mathrm{CO}_{2}$. For the preparation of cell microsomal fractions, cells were suspended in PBS and subjected to five rounds of freeze/thaw before gentle homogenization. The cell homogenate was centrifuged at $9000 \mathrm{~g}$ for 30 minutes at $4^{\circ} \mathrm{C}$, and the supernatant was further centrifuged at $105,000 \mathrm{~g}$ for 60 minutes at $4^{\circ} \mathrm{C}$. The microsomal pellet was resuspended in PBS and stored at $-80^{\circ} \mathrm{C}$. Total microsomal protein concentrations were determined using the BCA protein assay.

L- and D-Menthol Glucuronidation Assay. L- and D-MG formation was determined in HLMs (10 $\mu \mathrm{g}$ protein), HIMs (20 $\mu \mathrm{g}$ of protein), and UGTexpressing cell microsomes (15-20 $\mu \mathrm{g}$ of protein) after preincubation with alamethicin $(50 \mu \mathrm{g} / \mathrm{mg}$ of protein, resulting in pores within the microsomal membrane) for 10 minutes on ice. Incubations ( $20 \mu \mathrm{l}$, final volume) included $50 \mathrm{mM}$ Tris- $\mathrm{HCl}(\mathrm{pH} 7.4), 10 \mathrm{mM} \mathrm{MgCl}_{2}, 4 \mathrm{mM}$ UDP glucuronic acid, $2 \%$ bovine serum albumin, and either D- or L-menthol. Screening assays used $1.0 \mathrm{mM}$ D- or L-menthol as substrate, and kinetic analysis used a range of $0.02-2.5 \mathrm{mM}$ D- or L-menthol. Reactions were carried out at $37^{\circ} \mathrm{C}$ for 30 minutes and terminated by the addition of an equal volume of cold methanol and spiked with $2 \mu$ of L-MG-d $\mathrm{d}_{4}(1 \mathrm{ppm})$. The precipitate was removed by centrifugation at $16,000 \mathrm{~g}$ for 10 minutes at $4^{\circ} \mathrm{C}$, and the supernatant was analyzed by liquid chromatography tandem mass spectroscopy (LC-MS/MS) as described below. The rate of menthol glucuronidation was linear for up to 60 minutes. Each analysis was performed in triplicate.

NNAL-Gluc Inhibition Assay. L- and D-menthol inhibition of NNAL-Gluc formation in HLMs and UGT-overexpressing cell microsomes was performed as described previously using rac-NNAL $(1 \mathrm{mM})$ as substrate and either the D- or L-menthol enantiomers $(1.0-2500 \mu \mathrm{M})$ as inhibitors. Reactions were performed at $37^{\circ} \mathrm{C}$ for 60 minutes, terminated by the addition of an equal volume of cold methanol, and spiked with $2 \mu \mathrm{l}$ of NNAL-Gluc internal standard mix (NNAL$\mathrm{N}$-Gluc- $\mathrm{d}_{3}$ and NNAL-O-Gluc-d $\mathrm{d}_{5}, 2 \mathrm{ppm}$ each). Precipitate was removed by centrifugation at $16,000 \mathrm{~g}$ for 10 minutes at $4^{\circ} \mathrm{C}$, and the supernatant was analyzed by LC-MS/MS as described below. As described previously for in vitro NNAL glucuronidation assays, NNAL glucuronidation rates were linear for up to 2 hours (Chen et al., 2008a). Each analysis was performed in triplicate.

LC-MS/MS Analysis. For in vitro activity assays with HLMs, HIMs, or HEK293 UGT-overexpressing cell microsomes, LC separation of NNAL metabolites was achieved using an Acquity $\mathrm{H}$ class ultraperformance liquid chromatography [UPLC; Waters, Milford, MA]. NNAL-Gluc peaks were analyzed essentially as described previously (Kozlovich et al., 2015), with an HSS T3 $1.8-\mu \mathrm{m}$ column $(2.1 \times 100 \mathrm{~mm}$; Acquity; Waters $)$ at $30^{\circ} \mathrm{C}$ by gradient elution at a flow rate of $0.35 \mathrm{ml} / \mathrm{min}$ using the following conditions: 0.5 minute with $99 \%$ buffer A (5 mM ammonium formate with $0.01 \%$ formic acid) and $1 \%$ buffer B $(100 \% \mathrm{MeOH})$, followed by a linear gradient for 3.0 minutes to $20 \%$ buffer B, and a subsequent linear gradient for 1.0 minute to $95 \%$ buffer B. The column was subsequently washed with a linear gradient to $1 \%$ buffer $\mathrm{B}$ for 1.0 minute and re-equilibrated for 1.0 minute in $1 \%$ buffer $\mathrm{B}$.

MG peaks were analyzed using the same LC-MS/MS system with the column at $30^{\circ} \mathrm{C}$ with gradient elution at $0.30 \mathrm{ml} / \mathrm{min}$ using the following conditions: 0.5 minute with $95 \%$ buffer A (5 $\mathrm{mM}$ ammonium acetate); $5 \%$ buffer B ( $100 \%$ acetonitrile), followed by a linear gradient for 9.5 minutes to $25 \%$ buffer $\mathrm{A}$, and a subsequent linear gradient for 3 minutes to $5 \%$ buffer $\mathrm{A}$. Equilibrium was re-established after a 1-minute linear gradient to $95 \%$ buffer A.

The Waters Xevo TQD tandem mass spectrometer (MS) was equipped with a Zspray electrospray ionization interface operated in the positive ion mode for in vitro NNAL-Gluc detection, with capillary voltage at $0.6 \mathrm{kV}$. Nitrogen was used as both the cone gas and desolvation gas at 50 and $800 \mathrm{l} / \mathrm{h}$, respectively. Ultra-pure argon was used for collision-induced dissociation. The desolvation temperature and the ion source temperature were 500 and $150^{\circ} \mathrm{C}$, respectively. For the detection of NNAL glucuronides, the MS was operated in the multiple reaction monitoring mode (MRM) with the following transitions: NNAL- $N$-Gluc, MS transition of $386.2 \mathrm{~m} / \mathrm{z}>180.1 \mathrm{~m} / \mathrm{z}$ with cone voltage, and collision energy at 15 and $20 \mathrm{~V}$, respectively; NNAL-O-Gluc, MS transition of $386.2 \mathrm{~m} / \mathrm{z}>162.1 \mathrm{~m} / \mathrm{z}$ with the cone voltage and collision energy each at $15 \mathrm{~V}$.

MG detection was performed on the same Xevo TQD instrument with the electrospray interface operated in the negative-ion mode with capillary voltage at $2.0 \mathrm{kV}$. Nitrogen was used as both the cone gas and desolvation gas at 50 and 800 $1 / \mathrm{h}$, respectively. Ultrapure argon was used for collision-induced dissociation, and the desolvation temperature and the ion source temperature were 500 and $150^{\circ} \mathrm{C}$, respectively. For the detection of MGs, the MS was operated in the MRM mode with a transition of $331.0 \mathrm{~m} / \mathrm{z}>84.9 \mathrm{~m} / \mathrm{z}$ with cone voltage and collision energy at 46 and $24 \mathrm{~V}$, respectively.

For analysis of urine specimens, $2 \times 10-\mu 1$ aliquots of each specimen were spiked with either $5 \mu \mathrm{l}$ of an internal standard mixture that included NNAL-13C 6 ,

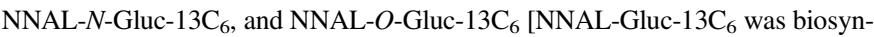
thesized from NNAL-13 $\mathrm{C}_{6}$ using a previously published method (Chen et al., 2016)], $0.1 \mathrm{ppm}$ each, or $5 \mu \mathrm{l}$ of $\mathrm{L}-\mathrm{MG}-\mathrm{d}_{4}$ (3 ppm). After the addition of $10 \mu \mathrm{l}$ of $0.5 \mathrm{M}$ ammonium formate, the mixture was vortexed thoroughly. All precipitate was removed by centrifugation at $16,000 \mathrm{~g}$ for 10 minutes at $4^{\circ} \mathrm{C}$. The supernatant was transferred into $350 \mu \mathrm{l}$ conical glass sample vials for LC-MS/MS analysis. MGs were detected and quantified using the same LC-MS/MS methods described above. Urinary NNAL and its metabolites were detected and quantified with minor changes from a previously described method (Chen et al., 2016) using an Acquity UPLC with an HSS T3 $(100 \times 2.1 \mathrm{~mm}, 1.8 \mu \mathrm{m})$ UPLC column (Waters) and a Xevo G2-S quadrupole time-of-flight (QTOF) MS. The LC method was performed using a $5-\mu 1$ sample injection volume, a $25^{\circ} \mathrm{C}$ column temperature and a flow rate of $0.20 \mathrm{ml} / \mathrm{min}$ using the following conditions: a 1-minute linear gradient of $100 \%$ buffer A ( $5 \mathrm{mM}$ ammonium formate with $0.01 \%$ formic acid) to $99 \%$ buffer A: $1 \%$ buffer B ( $100 \%$ acetonitrile), a subsequent isocratic gradient of $1 \%$ buffer $\mathrm{B}$ for 9 minutes, followed by a linear gradient for 8 minutes to $3 \%$ buffer B. After an additional 8 minutes at 3\% buffer B, the column was cleaned with $95 \%$ buffer B and re-equilibrated to the initial conditions before the next sample injection.

The Waters Xevo G2-S Qtof MS was operated in positive electrospray ionization MS/MS-sensitive mode, with capillary voltage at $0.6 \mathrm{kV}$. Nitrogen was used for both cone and desolvation gases at 50 and $800 \mathrm{l} / \mathrm{h}$, respectively. Ultrapure argon was used as the collision gas, with a flow rate of $0.1 \mathrm{l} / \mathrm{h}$ for collision-induced dissociation. The source temperature was $120^{\circ} \mathrm{C}$, desolvation gas temperature was $500^{\circ} \mathrm{C}$, and the dwell time for each ion was 0.1 second. The cone voltage was 15 , 25 , and $15 \mathrm{~V}$; the collision energies were 10,20 , and $15 \mathrm{~V}$ for NNAL, NNAL- $N$ Gluc, and NNAL- $O$-Gluc, respectively. The MS transition for quantification for NNAL- $N$-Gluc, NNAL- $O$-Gluc, NNAL, and respective internal standards (IS) are $386.2>180.124$ (IS: $392.2>186.144$ ), $386.2>162.115$ (IS: $392.2>168.135$ ) and $210.1>180.124$ (IS: $216.2>186.144$ ), respectively.

The MS transitions and LC retention times for each molecule were compared with purchased NNAL- $O$-Gluc, NNAL- $N$-Gluc, NNAL, and MG standards. The levels of NNAL-O-Gluc, NNAL- $N$-Gluc, free NNAL, and MG were quantified against a standard curve made from authenticated standards for NNAL-O-Gluc, NNAL- $N$-Gluc, free NNAL, or MG of known quantity (Toronto Research Chemicals). Each NNAL and NNAL-Gluc standard curve was linear from 10 to $0.005 \mathrm{ppm}$; MG standard curves were linear from 50 to $0.005 \mathrm{ppm}$. Free NNAL and NNAL glucuronides were measured simultaneously, as were L- and D-MG, as described above.

Urinary creatinine levels were determined as previously described (Chen et al., 2016). Briefly, $2 \mu \mathrm{l}$ of each urine specimen was diluted 1000-fold in water, with $10 \mu \mathrm{l}$ of the diluted sample mixed with $10 \mu 1$ of $0.1 \mathrm{ppm}$ for LC-MS/MS analysis using the same QToF LC-MS/MS system described above. The creatinine- $\mathrm{d}_{3}$ internal standard was also mixed into urine before dilution before LC-MS/MS analysis for a set of five randomly chosen urine specimens, and comparable results were obtained. The MS trace for quantification of creatinine is 114.06 (IS: 117.08), with a linear range of detection from 2 to $20,000 \mathrm{ppm}$.

A stable isotope dilution method was used for method validation and accuracy. The specificity of all LC-MS/MS methods were validated using positive and negative control samples, as well as by comparing peaks with those observed for purchased standards and isotope-labeled internal standards. Linearity was validated by $r^{2}>0.997$ for all standard curves. Assay precision was validated by repeated (three to five times) sample quantification, with a coefficient of variation less than $10 \%$. Since isotope-labeled internal standards were used in all LC-MS/MS analyses, matrix effects on analyte quantification was minimal. For quantification of urinary MG, NNAL, and NNAL-Glucs, urine specimens were directly spiked with IS and then analyzed by LC-MS/MS without sample extraction. Therefore, recovery or dilution effects were not a concern. Analyte quantification was based on the ratio of signal peak area versus the peak area of the IS. Range and median analyte levels were consistent with previous publications (Benowitz et al., 2010; Chen et al., 2016).

Statistical Analysis. Kinetic and inhibition constants, nonparametric ANOVA (Kruskal-Wallis) with Dunn's post-test, Student's $t$ test, and 
Human Liver Microsomes

A
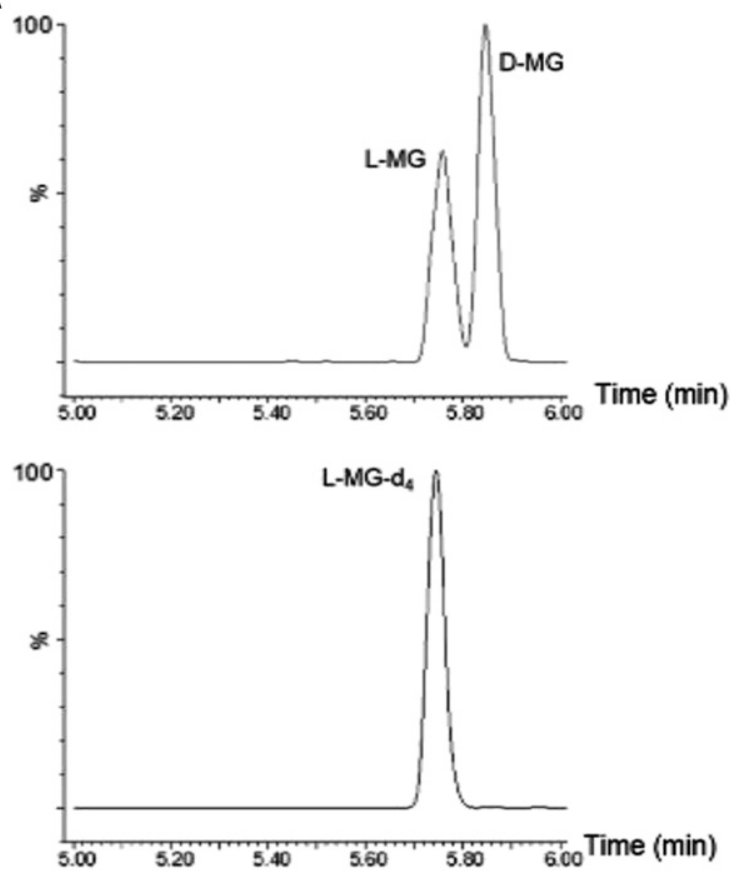

Urinary MG

B
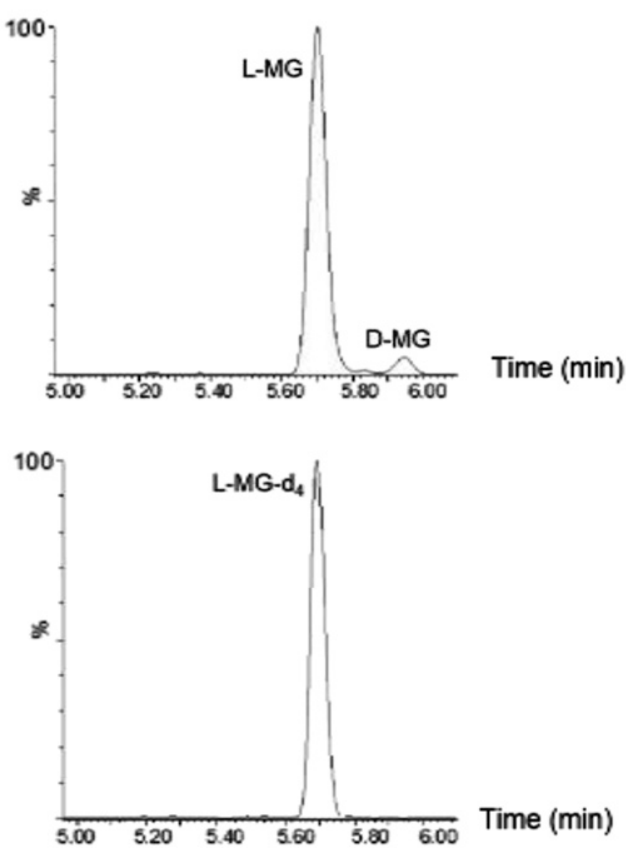

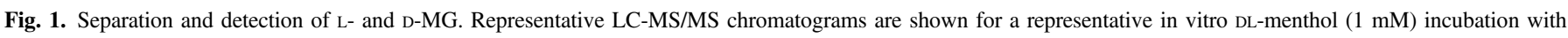

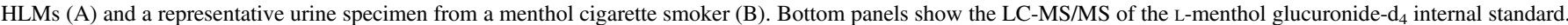

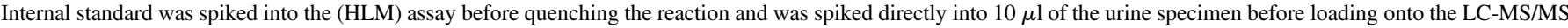
system.

Spearman correlations were determined using Prism version 7.0 (GraphPad Software, San Diego, CA).

\section{Results}

To develop a separation and detection method for L- and D-MG, DLmenthol was incubated with HLMs. As shown in Fig. 1, efficient separation of D- and L-MG peaks was observed using the LC-MS/MS method described in this study. This method produced two distinct peaks: L-MG with a retention time of approximately 5.76 minutes and D-MG with a retention time of approximately 5.85 minutes (Fig. 1A). The L-MG peak was confirmed by comparison with commercial L-MG-d ${ }_{4}$ IS (retention time $=5.75$ minutes; Fig. 1B). Whereas pure deuterated D-MG was not available as an IS, the second peak exhibited a different retention time with the same mass transition, suggesting that this peak corresponds to D-MG. The coefficient of variation for the detection of L-MG and/or D-MG from assays with DL-menthol, L-menthol, and D-menthol were $12 \%, 9 \%$, and $15 \%$, respectively.

To determine which UGTs form the glucuronide for either L- or D-menthol, 18 human UGTs were screened for glucuronidation activity using UGT-overexpressing cell microsomes. UGTs 1A9, 1A10, 2A1, 2A2, 2A3, 2B4, 2B7, and 2B17 exhibited detectable levels of glucuronidation activity for both menthol enantiomers (summarized in Supplemental Table 1). Whereas UGT1A7 exhibited detectable glucuronidating activity for L-menthol, no detectable activity was observed for D-menthol for this enzyme. UGTs 1A1, 1A3, 1A4, 1A5, 1A6, 1A8, 2B10, 2B11, and 2B15 all exhibited no detectable activity for either menthol enantiomer. UGT2B7 exhibited the lowest apparent $K_{\mathrm{M}}$

TABLE

Kinetics for L- and D-menthol with UGT-expressing human embryonic kidney cell line 293 (HEK293) $^{a, b}$

\begin{tabular}{|c|c|c|c|c|c|c|}
\hline \multirow{2}{*}{ Enzyme } & \multicolumn{3}{|c|}{ L-menthol } & \multicolumn{3}{|c|}{ D-menthol } \\
\hline & $K_{\mathrm{M}}(\mathrm{mM})$ & $V_{\max }{ }^{c}\left(\mathrm{pmol} \cdot \mathrm{mg}\right.$ protein $\left.{ }^{-1} \cdot \mathrm{min}^{-1}\right)$ & $V_{\max } / \mathrm{K}_{\mathrm{M}}^{c}\left(\mathrm{nl} \cdot \mathrm{mg}\right.$ protein $\left.{ }^{-1} \cdot \min ^{-1}\right)$ & $K_{\mathrm{M}}(\mathrm{mM})$ & $V_{\max }{ }^{c}\left(\mathrm{pmol} \cdot \mathrm{mg}\right.$ protein $\left.{ }^{-1} \cdot \min ^{-1}\right)$ & $V_{\max } / K_{\mathrm{M}}^{c}\left(\mathrm{nl} \cdot \mathrm{mg}\right.$ protein $\left.^{-1} \cdot \mathrm{min}^{-1}\right)$ \\
\hline UGT1A9 & $2.1 \pm 2.0$ & $3.1 \pm 2.2$ & 1.7 & $0.80 \pm 0.43$ & $8.6 \pm 2.3$ & 12 \\
\hline UGT1A10 & $4.1 \pm 0.9$ & $16 \pm 3.3$ & 3.9 & $1.9 \pm 1.2$ & $16 \pm 7.0$ & 8.9 \\
\hline UGT2A1 & $1.8 \pm 0.9$ & $28 \pm 7.2$ & 16 & $0.37 \pm 0.12$ & $42 \pm 3.6$ & 120 \\
\hline UGT2B7 & $0.35 \pm 0.03$ & $54 \pm 6.2$ & 155 & $0.33 \pm 0.12$ & $48 \pm 7.5$ & 154 \\
\hline UGT2B17 & $0.70 \pm 0.24$ & $4.0 \pm 1.3$ & 5.9 & $0.76 \pm 0.09$ & $10 \pm 1.7$ & 14 \\
\hline HLMs & $0.89 \pm 0.13$ & $4167 \pm 326$ & 4802 & $0.54 \pm 0.22$ & $2805 \pm 293$ & 5721 \\
\hline HIMs & $1.7 \pm 1.1$ & $1.8 \pm 0.90$ & 1.1 & $0.99 \pm 0.18$ & $2.3 \pm 0.25$ & 2.3 \\
\hline
\end{tabular}

HIM, human intestinal microsome; HLM, human liver microsome; UGT, UDP-glucuronosyltransferase.

${ }^{a}$ Data are expressed as the mean \pm S.D. of three independent experiments.

${ }^{b}$ Seventeen human UGTs were screened for L- D-menthol activity. UGTs 1A1, 1A3, 1A4, 1A5, 1A6, 1A8, 2B10 and $2 \mathrm{~B} 11$ exhibited no activity when incubated with either L- or D-menthol

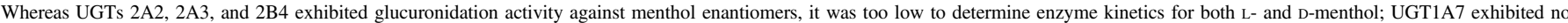
detectible activity for D-menthol, and its L-menthol glucuronidation activity was too low to determine enzyme kinetics.

${ }^{c}$ Units are expressed per milligram total microsomal protein. 
TABLE 2

L- and D-menthol inhibition constants $\left(\mathrm{IC}_{50}\right)$ for HLM and UGT-expressing cell microsomes for NNAL glucuronide formation ${ }^{a}$

\begin{tabular}{llccc}
\hline & & $\begin{array}{c}\text { NNAL- } N \text {-Gluc } \\
(\mu \mathrm{M})\end{array}$ & $\begin{array}{c}(R) \text {-NNAL- } O \text {-Gluc } \\
(\mu \mathrm{M})\end{array}$ & $\begin{array}{c}(S) \text {-NNAL- } O \text {-Gluc } \\
(\mu \mathrm{M})\end{array}$ \\
\hline HLM & 100 & 750 & 660 \\
LGT1A9 & NA & 632 & 689 \\
& UGT1A10 & NA & 2309 & $>2500$ \\
& UGT2B7 & NA & NA & 163 \\
& UGT2B10 & 236 & NA & NA \\
& UGT2B17 & NA & 927 & NA \\
& HLM & 50 & 1265 & 690 \\
& UGT1A9 & NA & 1480 & 1215 \\
UGT1A10 & NA & 1419 & $>2500$ \\
UGT2B7 & NA & NA & 343 \\
& UGT2B10 & 202 & NA & NA \\
& UGT2B17 & NA & 995 & NA \\
\hline
\end{tabular}

${ }^{a}$ Data are expressed as the mean of three independent experiments.

${ }^{b} \mathrm{NA}$, not applicable (reaction not expected to produce the product).

$(0.35 \mu \mathrm{M})$ for L-menthol, followed by UGT2B17 < UGT2A1 UGT1A9 < UGT1A10 (Supplemental Fig. 1; Table 1). A similar pattern was observed for D-menthol, with UGTs 2B7 and 2A1 exhibiting the lowest apparent $K_{\mathrm{M}}$ values $(0.33$ and $0.37 \mu \mathrm{M}$, respectively), followed by UGT2B17 UGT1A9 < UGT1A10. The apparent $K_{\mathrm{M}}$ values observed by kinetic analysis for active UGT-overexpressing cell microsomes ranged from 0.35 to $4.1 \mathrm{mM}$ for L-menthol and $0.22-1.9 \mathrm{mM}$ for D-menthol and were comparable to that observed for HLMs ( 0.89 and $0.54 \mathrm{mM}$ for L- and D-menthol, respectively) and HIMs (1.7 and $0.99 \mathrm{mM}$ for L- and D-menthol, respectively) (Table 1). Kinetic parameters could not be obtained for UGTs 1A7, 2A2, 2A3, and 2B4 because of low overall activity. Except for UGT2B7, all the UGTs, as well as HLMs and HIMs, exhibited higher turnover rates $\left(V_{\max } / K_{\mathrm{M}}\right)$ for D-menthol than L-menthol (Table 1), suggesting that active UGTs have a higher clearance for D-menthol as a substrate. There was a 1220- and 2315-fold higher $V_{\max } / K_{\mathrm{M}}$ observed for HLMs than HIMs for D- and L-menthol, respectively.

To determine the potential impact of menthol on the inhibition of NNAL glucuronidation, assays were initially performed with HLMs, $1 \mathrm{mM}$ rac-NNAL, and each menthol enantiomer ranging in concentration from $1.0 \mu \mathrm{M}$ to $2.5 \mathrm{mM}$, with individual NNAL glucuronides detected by LC-MS/MS as described in the Materials and Methods. $\mathrm{IC}_{50}$ values were similar when inhibition assays were performed at either 30 minutes (data not shown) or 60 minutes. Both L- and D-menthol showed some level of inhibition for the formation of each NNAL glucuronide product in HLMs, with the strongest inhibition exhibited for NNAL- $N$-Gluc formation ( $\mathrm{IC}_{50}$ values of 100 and $50 \mu \mathrm{M}$, respectively; Fig. 2 and Table 2). The $\mathrm{IC}_{50}$ values were 6.6- and 13.8-fold higher for $(S)$-NNAL-O-Gluc versus NNAL- $N$-Gluc formation and 7.5- and 25.4fold higher for $(R)$-NNAL- $O$-Gluc versus NNAL- $N$-Gluc formation, for $\mathrm{L}-$ and D-menthol, respectively, in HLMs. Whereas the $\mathrm{IC}_{50}$ value was 2fold higher for L- versus D-menthol for NNAL- $N$-Gluc formation, D-menthol exhibited a 1.7-fold higher $\mathrm{IC}_{50}$ value compared with L-menthol for $(R)$-NNAL- $O$-Gluc formation; no difference was observed between $\mathrm{L}$ - and D-menthol for the formation of $(S)$-NNAL-O-Gluc $\left(\mathrm{IC}_{50}\right.$ values $=660$ and $690 \mu \mathrm{M}$, respectively).

The formation of NNAL- $N$-Gluc by UGT2B10 was similarly inhibited by both L- and D-menthol $\left(\mathrm{IC}_{50}\right.$ values $=236$ and $202 \mu \mathrm{M}$, respectively); consistent with that observed in previous studies (Muscat et al., 2009), no NNAL- $N$-Gluc formation was detected for cell microsomes overexpressing UGTs 1A9, 1A10, 2B7, and $2 \mathrm{~B} 17$ (with or without the addition of $\mathrm{D}$ - or L-menthol). The highest levels of inhibition of NNAL-O-Gluc formation by menthol enantiomers was observed for UGT2B7 for $(S)$-NNAL-O-Gluc $\left(\mathrm{IC}_{50}\right.$ values $=163$ and $343 \mu \mathrm{M}$ for L- and D-menthol, respectively). Less inhibition was observed for menthol enantiomers of UGT1A9and UGT2B17-induced NNAL-O-Gluc formation; neither menthol enantiomer exhibited strong inhibition of the extrahepatic UGT1A10.

To examine the potential effect of menthol inhibition on NNAL-Gluc formation in vivo, a panel of 100 urine specimens was examined from smokers recruited into the Southern Community Cohort Study. As shown in Table 3,50\% of the subjects indicated that they were smokers of mentholated cigarettes; subjects smoked an average of 15 cigarettes/day. Each specimen was analyzed for levels of D-MG, L-MG, $(R)$-NNAL- $O$-Gluc, $(S)$-NNAL- $O$-Gluc, NNAL- $N$-Gluc, and free NNAL. MG was detected in all 50 menthol smokers and in 47 of the 50 nonmenthol smokers. The fact that three of the nonmenthol smokers exhibited no detectable level of MG suggested method specificity. Identification of the MG peak was verified by comparison with the retention time of the heavy isotope-labeled IS and a purchased analytical standard (Fig. 1). Blank samples were analyzed by LC-MS/MS immediately after individual urine samples and showed no sample carryover (data not shown). Total urinary MG levels ranged from 0 to $255 \mu \mathrm{g} / \mathrm{mg}$ creatinine. L-MG was the most prevalent menthol metabolite in these urine specimens. Urinary L-MG and D-MG were detected in 97 and 44 of the subjects, respectively, with L-MG detectable in specimens from 50 menthol smokers and 47 nonmenthol smokers and D-MG detectable in 18 menthol smokers and 26 nonmenthol smokers. In only three specimens from nonmenthol smokers was no MG (L- or D-) detected. When detectable ( $n=44$ specimens), urinary D-MG comprised an average of $2.8 \%$ of total MG. For the 97 specimens with detectable MG (either L- and/or D-menthol), D-menthol comprised an average of $1.3 \%$ of total MG. The range in the ratio of D-MG:total MG in the 44 specimens with detectable D-MG was $0.0010-0.20$. No significant differences in MG levels were observed for specimens from smokers who self-reported being menthol versus nonmenthol smokers (Fig. 3A). In addition, no significant differences in urinary MG levels were found between specimens from white versus black menthol smokers $(P=0.25)$ or white versus black nonmenthol smokers $(P=$ 0.51 ; data not shown). When stratifying specimens based on levels of total urinary MG (Fig. 3B), there were more specimens from nonmenthol smokers versus menthol smokers in the two lowest groups (0-5 and 6-10 $\mu \mathrm{g} \mathrm{MG} / \mathrm{mg}$ creatinine) but also in the highest group $(76+\mu \mathrm{g}$ $\mathrm{MG} / \mathrm{mg}$ creatinine). Although the levels of MG in specimens from menthol smokers had a wider distribution, the curve was skewed to the lower MG levels, with a small number of specimens exhibiting high MG levels. A large gap in distribution was observed with no

TABLE 3

Study subject demographics

\begin{tabular}{lccc}
\hline & $\begin{array}{c}\text { All Subjects }(\mathrm{N}= \\
100)\end{array}$ & $\begin{array}{c}\text { Nonmenthol Smokers } \\
(n=50)\end{array}$ & $\begin{array}{c}\text { Menthol Smokers } \\
(n=50)\end{array}$ \\
\hline Age, mean & $49 \mathrm{y}$ & $52 \mathrm{y}$ & $47 \mathrm{y}$ \\
Age, range & $40-66 \mathrm{y}$ & $40-66 \mathrm{y}$ & $40-61 \mathrm{y}$ \\
Sex & $56 \%$ Female & $58 \%$ Female & $54 \%$ Female \\
Race/ethnicity & 34\% White & $62 \%$ White & $6 \%$ White \\
& $60 \%$ Black & $28 \%$ Black & $92 \%$ Black \\
& $1 \%$ Hispanic & & $2 \%$ Hispanic \\
Cigarettes/day, & $5 \%$ Mixed race & $10 \%$ Mixed race & \\
mean (range) & $15(3-40)$ & $20(5-40)$ & $11(3-30)$ \\
Pack-years, mean & & & $15(1-41)$ \\
(range) & $25(1-98)$ & $35(6-98)$ & \\
& & & \\
\hline
\end{tabular}


NNAL- $N$-gluc

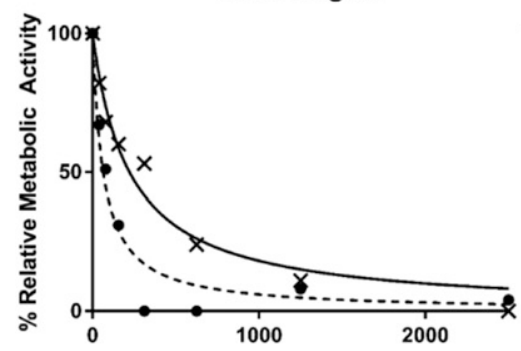

(R)-NNAL-O-gluc

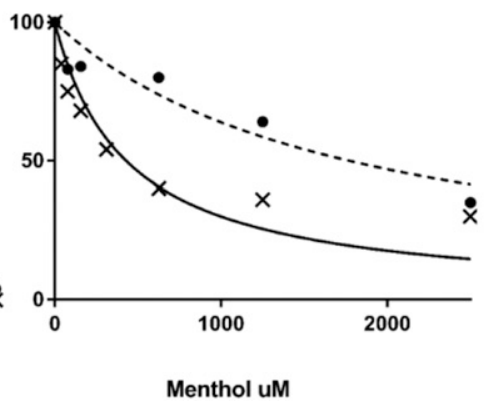

(S)-NNAL-O-gluc

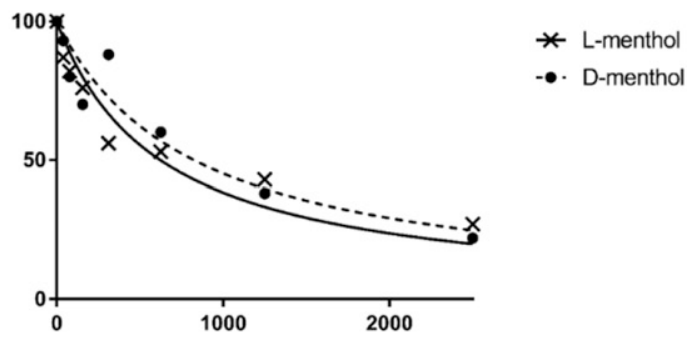

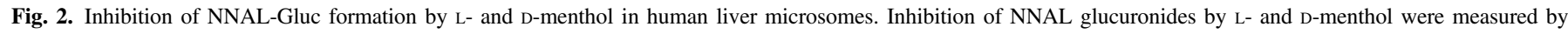

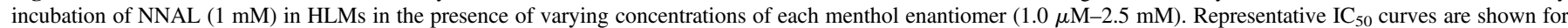
the inhibition of each NNAL glucuronide formation by L-menthol $(x)$ and D-menthol $(\bullet)$.

specimens within the MG levels ranging from 46 to $70 \mu \mathrm{g} \mathrm{MG} / \mathrm{mg}$ creatinine.

To assess more completely the potential interaction between menthol and NNAL detoxification, NNAL and its glucuronides were measured in all 100 urine specimens (Table 4). NNAL metabolites were detectable in all the urine specimens analyzed, with one specimen falling below the limit of quantification for $(R)$-NNAL- $O$-Gluc. The levels of total urinary NNAL were positively correlated with the number of cigarettes per day $(r=0.4)$. No significant differences were found between specimens from white and black smokers for $(S)$-NNAL- $O$-Gluc $(P=0.28),(R)$ NNAL- $O$-Gluc $(P=0.51)$, NNAL- $N$-Gluc $(P=0.82)$, or free NNAL $(P=0.77)$, suggesting that race was not a factor when assessing the levels of these urinary metabolites. The levels of each urinary metabolite (MG, free NNAL, and each NNAL-Gluc) were similar between smokers of menthol and nonmenthol branded cigarettes (Table 5). No significant correlations were observed for any of the urinary NNAL glucuronides (or for free NNAL) compared with total urinary MG in the 100 specimens (Spearman coefficient test; data not shown). No significant difference was observed in the levels of free NNAL between MG tertile groups when examining free NNAL alone (Supplemental Table 2) or as a ratio with total NNAL (results not shown). To normalize individual NNAL metabolite levels between individuals, each of the urinary NNAL-Glucs was determined as a ratio with free NNAL as the denominator. When specimens were stratified by tertiles based on levels of total urinary MG (termed low, intermediate, and high), significantly lower levels of urinary NNAL- $N$-Gluc (as a ratio with free NNAL) were observed in both the intermediate $(P<0.01)$ and high $(P<0.05)$ urinary MG groups compared with the low urinary MG group (Fig. 4). Specimens with intermediate and high urinary MG levels exhibited similar NNAL- $N$-Gluc levels. Whereas a trend toward lower
(R)-NNAL-O-Gluc levels was also observed in the higher MG tertile groups, these differences were not significant (Fig. 4). No significant difference was observed for $(S)$-NNAL-O-Gluc between different urinary MG groups. No significant differences in the levels of any of the NNAL-Glucs were observed when using total NNAL as the denominator (results not shown).

\section{Discussion}

In the present study, the metabolism of menthol was explored by using a panel of 18 human UGTs that were screened for MG formation activity. UGTs 1A9, 1A10, 2A1, 2B7, and 2B17 all exhibited relatively high glucuronidation affinity for both $\mathrm{L}$ - and D-menthol, with $K_{\mathrm{M}}$ values similar to those observed in HLMs and HIMs. The activity observed for UGT2B7 in the present study $\left(K_{\mathrm{M}}=0.35 \mu \mathrm{M}\right)$ is consistent with that observed previously for UGT2B7 against L-menthol (Bhasker et al., 2000). The fact that UGT1A3 exhibited no activity against menthol enantiomers in the present study is also consistent with the lack of activity against menthol shown in previous studies (Green and Tephly, 1996). UGTs 2A1 and 1A10 are extrahepatic enzymes that are expressed in digestive tract tissues (Zheng et al., 2002; Dellinger et al., 2006; Bushey et al., 2011) and likely contribute to the MG formation observed in HIMs. UGTs 1A9, 2B7, and 2B17 are hepatically expressed enzymes (Zheng et al., 2002; Jones and Lazarus, 2014) that could all be playing a role in MG formation in HLMs. UGTs $2 \mathrm{~A} 1$ and 2B7 exhibited the highest affinity for D-menthol, whereas UGTs 2B7 and 2B17 exhibited the highest affinity for L-menthol. Whereas previous studies suggested that UGT1A4 exhibited glucuronidation activity against menthol enantiomers (Green and Tephly, 1996), no detectable activity was observed for this enzyme in the current study. This

TABLE 4

Urinary NNAL and NNAL glucuronide levels in smokers by race ${ }^{a}$

\begin{tabular}{|c|c|c|c|c|}
\hline \multicolumn{5}{|c|}{ Nanograms per Milligram Creatinine } \\
\hline & $(S)$-NNAL-O-Gluc & $(R)$-NNAL- $O$-Gluc & NNAL- $N$-Gluc & Free NNAL \\
\hline \multicolumn{5}{|c|}{ White smokers } \\
\hline Mean & $0.64 \pm 0.062$ & $0.18 \pm 0.020$ & $0.29 \pm 0.026$ & $0.16 \pm 0.019$ \\
\hline Range & $0.074-1.66$ & $0.22-0.47$ & $0.076-0.69$ & $0.050-0.51$ \\
\hline \multicolumn{5}{|c|}{ Black smokers } \\
\hline Mean & $0.54 \pm 0.15$ & $0.16 \pm 0.053$ & $0.30 \pm 0.14$ & $0.21 \pm 0.092$ \\
\hline Range & $0.051-8.90$ & $0-3.2$ & $0.017-8.5$ & $0.009-5.6$ \\
\hline \multicolumn{5}{|c|}{ All smokers } \\
\hline Mean & $0.56 \pm 0.090$ & $0.16 \pm 0.033$ & $0.29 \pm 0.085$ & $0.19 \pm 0.056$ \\
\hline Range & $0.051-8.90$ & $0-3.2$ & $0.017-8.5$ & $0.009-5.6$ \\
\hline
\end{tabular}

${ }^{a}$ Values are expressed as mean \pm S.E. 
TABLE 5

Urinary NNAL, NNAL glucuronides, and menthol glucuronides in menthol and nonmenthol smokers ${ }^{a}$

\begin{tabular}{lcc}
\hline Urinary Metabolites $^{b}$ & Nonmenthol Smokers & Menthol Smokers \\
\hline NNAL- $N$-Gluc & $0.25 \pm 0.020$ & $0.33 \pm 0.17$ \\
$(R)$-NNAL-O-Gluc & $0.16 \pm 0.015$ & $0.17 \pm 0.064$ \\
(S)-NNAL-O-Gluc & $0.55 \pm 0.043$ & $0.57 \pm 0.18$ \\
Free NNAL & $0.15 \pm 0.017$ & $0.22 \pm 0.11$ \\
Total NNAL & $1.1 \pm 0.083$ & $1.3 \pm 0.52$ \\
L-MG & $11.7 \pm 5.5$ & $15.8 \pm 2.8$ \\
D-MG & $0.15 \pm 0.065$ & $0.062 \pm 0.043$ \\
Total-MG & $11.9 \pm 5.50$ & $15.9 \pm 2.8$ \\
\hline
\end{tabular}

${ }^{a}$ Values are expressed as mean \pm S.E.

${ }^{b}$ Metabolite values are in units of micorgrams per milligram of creatinine.

difference in activity may be due to differences in assay sensitivity between studies.

Racemic, DL-menthol was previously shown to inhibit the formation of both NNAL- $N$-Gluc and NNAL- $O$-Gluc formation in HLMs (Muscat et al., 2009). NNAL-O-Gluc formation is catalyzed by several of the same UGTs (i.e., 1A9, 1A10, 2B7, and 2B17) (Balliet et al., 2010; Kozlovich et al., 2015, 2019) that are also most active against menthol enantiomers. In the current study, the individual L- and D-menthol enantiomers were further studied as potential inhibitors of these UGTs, as well as UGT2B10, which is known to be the primary enzyme involved in NNAL- $N$-Gluc formation (Chen et al., 2008b, 2016; Kozlovich et al., 2015) and is expressed in several tobacco-related cancer tissues (Jones and Lazarus, 2014; Kozlovich et al., 2019). Whereas L- and D-menthol exhibited the strongest inhibition potential for formation of NNAL- $N$-Gluc in HLMs, each enantiomer also exhibited some level of inhibition for HLM formation of $(R)$ - and $(S)$-NNAL$O$-Gluc. When each UGT enzyme was individually assayed for inhibition, both menthol enantiomers exhibited high inhibition potential for UGT2B7-mediated formation of (S)-NNAL-O-Gluc. These data are similar to those from other studies in which menthol and other mercaptoid alcohols have been associated with the inhibition of UGT2B7 activity (Ishii et al., 2012). A similarly high inhibition potential was observed for UGT2B10-mediated formation of NNAL- $N$-Gluc. This inhibition of the hepatically expressed UGT2B7 and UGT2B10 is consistent with the inhibition of NNAL-O-Gluc and NNAL- $N$-Gluc observed previously in HLMs (Muscat et al., 2009).

Many studies have examined menthol versus nonmenthol smokers in an attempt to determine the impact of menthol on tobacco-related diseases, with several studies measuring MG as a potential biomarker for identification of menthol or nonmenthol cigarettes smokers. For example, one study indicated that the levels of urinary menthol (measured as MG) were not correlated with the use of menthol versus nonmenthol cigarettes (Benowitz et al., 2010), whereas another study found significantly higher MG levels in the blood of menthol versus nonmenthol smokers (Hsu et al., 2017). Consistent with these studies, results from the present study indicated that the levels of urinary MG were not correlated with subjects self-identifying as menthol or nonmenthol cigarette smokers. These studies are consistent with the hypothesis that menthol branding is not an accurate method of examining the effects of menthol on tobacco-induced diseases.

The analysis of potential menthol-induced inhibition of NNALGluc formation in vivo was performed in the present study by stratifying smokers into groups based on quantified levels of urinary MG rather than by menthol versus nonmenthol cigarette-branding type.

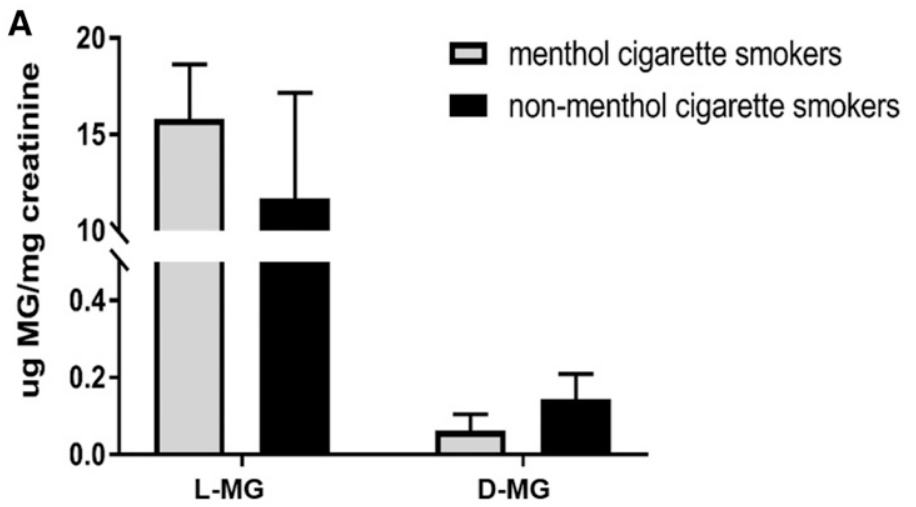

B

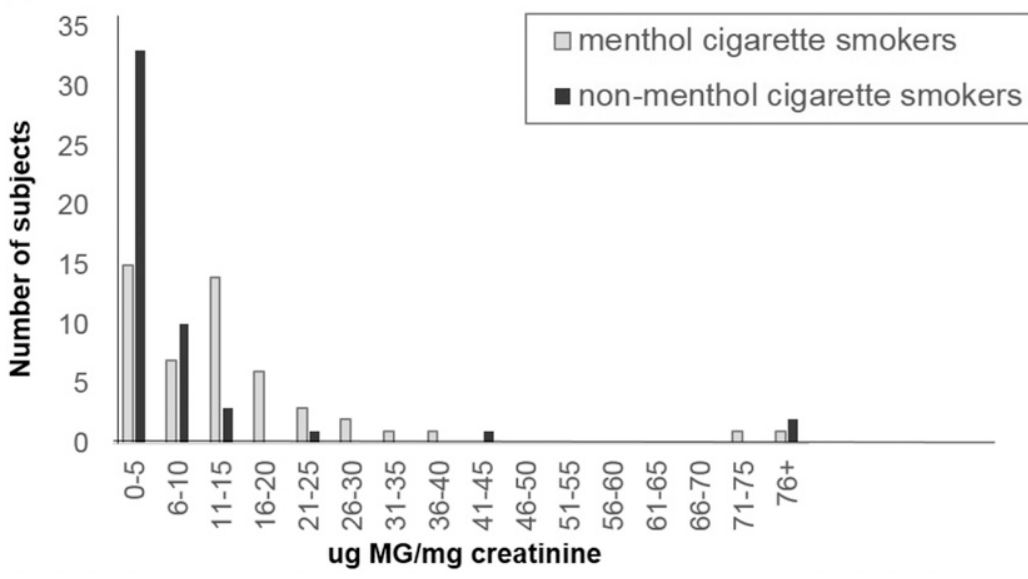

Fig. 3. Levels of menthol glucuronides stratified by menthol and nonmenthol cigarette smokers. Levels of $\mathrm{L}^{-}$and D-menthol glucuronides were quantified in the urine of smokers from menthol $(n=50)$ and nonmenthol $(n=50)$ cigarette smokers. Menthol glucuronides were analyzed by LC-MS/MS and were normalized to levels of creatinine. Subjects were stratified by menthol versus nonmenthol smoker groups based on cigarette brand labeling. (A) Menthol and nonmenthol branded smoking groups were analyzed for levels of urinary L- and D-menthol glucuronide and normalized based on levels of urinary creatinine. Bars represent mean ( \pm S.E.M.). (B) Histogram showing the number of menthol versus the number of nonmenthol smoking subjects (based on cigarette branding) at different total urinary MG levels. Subjects (nonmenthol, $n=3$ ) with MG concentrations below the limit of quantification are included in the $0-5 \mu \mathrm{g} / \mathrm{mg}$ creatinine bar. Bars represent the number of subjects in each category. 
NNAL-N-Gluc

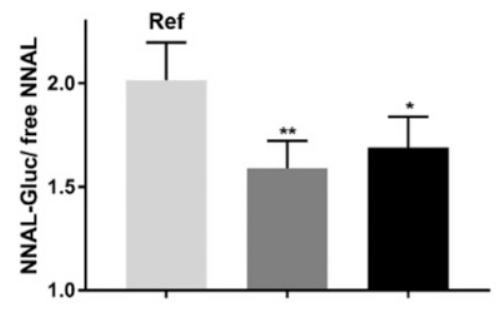

(R)-NNAL-O-Gluc

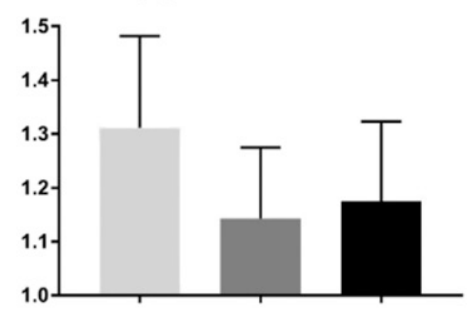

(S)-NNAL-O-Gluc

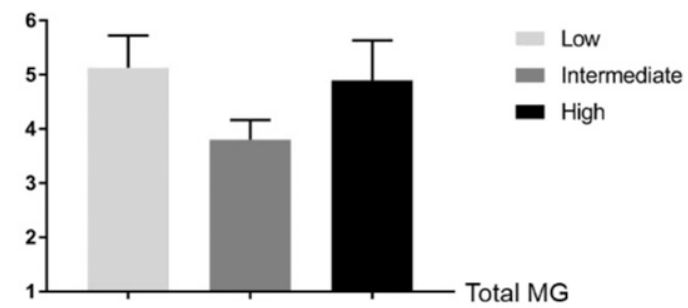

Subjects stratified by levels of urinary MG

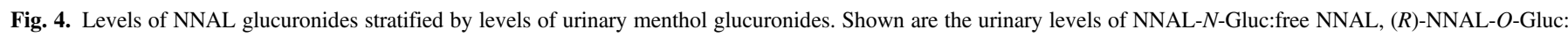

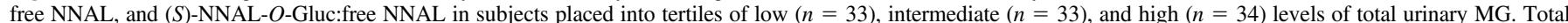

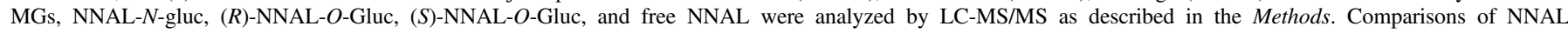

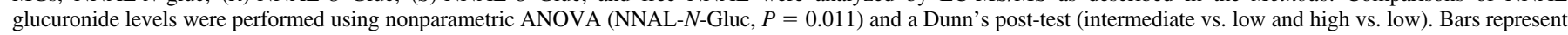
mean values $( \pm$ S.E. $) . * P<0.05 ; * * P<0.01$.

Interestingly, the levels of urinary D-MG were relatively low compared with the levels of urinary L-menthol, comprising, on average, $1.3 \%$ of the total menthol exposure for specimens from smokers with detectable urinary menthol. The group with the lowest urinary MG levels exhibited the highest levels of urinary NNAL- $N$-Gluc, suggesting a potential interaction between menthol and NNAL- $N$-Gluc formation, likely mediated by UGT2B10 based on the inhibition of UGT2B10 by menthol enantiomers in vitro. These data are consistent with the inhibitory effects observed with DL-menthol in HLMs in previous studies (Muscat et al., 2009). A similar but nonsignificant trend was observed for $(R)$-NNAL- $O$-Gluc formation, an effect potentially resulting from menthol inhibition of the $(R)$-NNAL- $O$-Gluc-forming enzyme, UGT2B17. A possible confounder was that UGT2B17, which plays an important role in $(R)$-NNAL-O-Gluc formation (Kozlovich et al., 2015; Chen et al., 2016), has a prevalent copy number variant (minor allele frequency $=0.30$ in white subjects) (Geer et al., 2010)] that was not examined in this population. To examine more completely the potential inhibitory effects of menthol on $(R)$-NNAL- $O$-Gluc formation, a larger smoking population is required.

Interestingly, the inhibition of $(S)$-NNAL-O-Gluc formation was observed for menthol enantiomers using UGT2B7-expressed cell microsomes in the current study. Although this could be due in part to the large variability in $(S)$-NNAL-O-Gluc formation observed between subjects, it is also likely that, consistent with other studies (Kozlovich et al., 2015; Chen et al., 2016), other UGTs involved in (S)-NNAL$O$-Gluc formation that are not as inhibited by menthol, including UGT1A9, may be important in hepatic $(S)$-NNAL- $O$-Gluc formation in addition to UGT2B7. Whereas a trend toward lower (R)-NNAL-O-Gluc levels were also observed in the higher MG tertile groups in the present study, these differences were not significant, suggesting that larger studies are required to examine fully this potential effect.

Although at lower levels than in menthol-branded cigarettes, menthol is also present in cigarettes classified as "nonmenthol" (TPSAC, 2011). The levels of menthol in nonmenthol cigarettes may still be at levels which could inhibit NNAL detoxification, especially in cases where the levels of menthol in nonmenthol cigarettes still far exceed the levels of NNK per cigarette. Nonmenthol cigarettes can contain up to $0.07 \mathrm{mg}$ of menthol per cigarette (Ai et al., 2016), whereas NNK levels are more than 10-fold lower (Ding et al., 2008; Rickert et al., 2008). Therefore, menthol content in nonmenthol cigarettes could have been important confounders in previous epidemiologic studies examining the role of menthol as a factor in lung cancer risk (comparing "menthol" vs. "nonmenthol" smokers); however, menthol is an additive in many edible and topical products and may have been consumed by some of the nonmenthol (as well as menthol) cigarette-smoking subjects for whom urine was analyzed in this study, potentially affecting the levels of urinary MG detected in these subjects. A confounder when considering edible menthol products as an inhibitor of NNAL metabolism is the potential for differential glucuronidation of menthol by extrahepatic UGTs that are expressed in the digestive tract (i.e., UGTs 1A7, 1A8, 1A10). Limitations of the present study include the fact that no information regarding recent menthol consumption or exposure from other sources was collected from recruited subjects at the time of urine collection. Additionally, there could be racial and/or gender variation in creatinine formation; the sample size used in the present study was not large enough to separate by either race or gender.

In summary, both menthol and NNAL are metabolized by some of the same UGT enzymes. Higher levels of urinary MG were correlated with decreases in urinary NNAL- $N$-Gluc in smokers, suggesting that the presence of menthol could potentially lead to NNAL being metabolized by different metabolic pathways, which could subsequently increase the opportunity for NNAL to result in increased DNA damage and increase the potential of tobacco-related cancers. The data presented in this study suggest that additional studies are required to delineate more clearly the relationship between menthol, tobacco carcinogen detoxification, and cancer risk

\section{Acknowledgments}

We thank the Mass Spectrometry Core facility at Washington State University Spokane for help with LC-MS/MS.

\section{Authorship Contributions}

Participated in research design: Kozlovich, Watson, Chen, Lazarus.

Conducted experiments: Kozlovich, Watson, Chen.

Contributed new reagents or analytic tools: Kozlovich, Chen, Lazarus.

Performed data analysis: Kozlovich, Watson, Chen, Lazarus.

Wrote or contributed to the writing of the manuscript: Kozlovich, Watson, Chen, Lazarus.

\section{References}

Ai J, Taylor KM, Lisko JG, Tran H, Watson CH, and Holman MR (2016) Menthol content in US marketed cigarettes. Nicotine Tob Res 18:1575-1580.

Balliet RM, Chen G, Dellinger RW, and Lazarus P (2010) UDP-glucuronosyltransferase 1A10: activity against the tobacco-specific nitrosamine, 4-(methylnitrosamino)-1-(3-pyridyl)-1-butanol, and a potential role for a novel UGT1A10 promoter deletion polymorphism in cancer susceptibility. Drug Metab Dispos 38:484-490.

Benowitz NL, Bernert JT, Caraballo RS, Holiday DB, and Wang J (2009) Optimal serum cotinine levels for distinguishing cigarette smokers and nonsmokers within different racial/ethnic groups in the United States between 1999 and 2004. Am J Epidemiol 169:236-248. 
Benowitz NL, Dains KM, Dempsey D, Havel C, Wilson M, and Jacob P III (2010) Urine menthol as a biomarker of mentholated cigarette smoking. Cancer Epidemiol Biomarkers Prev 19:3013-3019. Benowitz NL, Dains KM, Dempsey D, Wilson M, and Jacob P (2011) Racial differences in the relationship between number of cigarettes smoked and nicotine and carcinogen exposure. Nicotine Tob Res 13:772-783.

Bhasker CR, McKinnon W, Stone A, Lo AC, Kubota T, Ishizaki T, and Miners JO (2000) Genetic polymorphism of UDP-glucuronosyltransferase 2B7 (UGT2B7) at amino acid 268: ethnic diversity of alleles and potential clinical significance. Pharmacogenetics 10:679-685.

Bhatia SP, McGinty D, Letizia CS, and Api AM (2008) Fragrance material review on d-menthol. Food Chem Toxicol 46 (Suppl 11):S215-S217.

Blot WJ, Cohen SS, Aldrich M, McLaughlin JK, Hargreaves MK, and Signorello LB (2011) Lung cancer risk among smokers of menthol cigarettes. J Natl Cancer Inst 103:810-816.

Brooks DR, Palmer JR, Strom BL, and Rosenberg L (2003) Menthol cigarettes and risk of lung cancer. Am J Epidemiol 158:609-620.

Bushey RT, Chen G, Blevins-Primeau AS, Krzeminski J, Amin S, and Lazarus P (2011) Characterization of UDP-glucuronosyltransferase 2A1 (UGT2A1) variants and their potential role in tobacco carcinogenesis. Pharmacogenet Genomics 21:55-65.

Caraballo RS, Giovino GA, Pechacek TF, Mowery PD, Richter PA, Strauss WJ, Sharp DJ, Eriksen MP, Pirkle JL, and Maurer KR (1998) Racial and ethnic differences in serum cotinine levels of cigarette smokers: Third National Health and Nutrition Examination Survey, 1988-1991. JAMA 280:135-139.

Carpenter CL, Jarvik ME, Morgenstern H, McCarthy WJ, and London SJ (1999) Mentholated cigarette smoking and lung-cancer risk. Ann Epidemiol 9:114-120.

Celebucki CC, Wayne GF, Connolly GN, Pankow JF, and Chang EI (2005) Characterization of measured menthol in 48 U.S. cigarette sub-brands. Nicotine Tob Res 7:523-531.

Chen G, Dellinger RW, Gallagher CJ, Sun D, and Lazarus P (2008a) Identification of a prevalent functional missense polymorphism in the UGT2B10 gene and its association with UGT2B10 inactivation against tobacco-specific nitrosamines. Pharmacogenet Genomics 18:181-191.

Chen G, Dellinger RW, Sun D, Spratt TE, and Lazarus P (2008b) Glucuronidation of tobaccospecific nitrosamines by UGT2B10. Drug Metab Dispos 36:824-830.

Chen G, Luo S, Kozlovich S, and Lazarus P (2016) Association between glucuronidation genotypes and urinary NNAL metabolic phenotypes in smokers. Cancer Epidemiol Biomarkers Prev 25:1175-1184

Chung CJ, Pu YS, Shiue HS, Lee HL, Lin P, Yang HY, Su CT, and Hsueh YM (2013) 4 (Methylnitrosamino)-1-(3-pyridyl)-1-butanone (NNK) metabolism-related enzymes gene polymorphisms, NNK metabolites levels and urothelial carcinoma. Toxicol Lett 216:16-22.

Clark PI, Gautam S, and Gerson LW (1996) Effect of menthol cigarettes on biochemical markers of smoke exposure among black and white smokers. Chest 110:1194-1198.

Coultas DB, Gong H Jr, Grad R, Handler A, McCurdy SA, Player R, Rhoades ER, Samet JM, Thomas A, and Westley M (1994) Respiratory diseases in minorities of the United States. Am J Respir Crit Care Med 149:S93-S131.

Daraei P and Moore CE (2015) Racial disparity among the head and neck cancer population. $J$ Cancer Educ 30:546-551.

Dellinger RW, Fang JL, Chen G, Weinberg R, and Lazarus P (2006) Importance of UDPglucuronosyltransferase 1A10 (UGT1A10) in the detoxification of polycyclic aromatic hydrocarbons: decreased glucuronidative activity of the UGT1A10139Lys isoform. Drug Metab Dispos 34:943-949.

Ding YS, Zhang L, Jain RB, Jain N, Wang RY, Ashley DL, and Watson CH (2008) Levels of tobacco-specific nitrosamines and polycyclic aromatic hydrocarbons in mainstream smoke from different tobacco varieties. Cancer Epidemiol Biomarkers Prev 17:3366-3371.

Eccles R, Griffiths DH, Newton CG, and Tolley NS (1988) The effects of D and L isomers of menthol upon nasal sensation of airflow. J Laryngol Otol 102:506-508.

Geer LY, Marchler-Bauer A, Geer RC, Han L, He J, He S, Liu C, Shi W, and Bryant SH (2010) The NCBI BioSystems database. Nucleic Acids Res 38:D492-D496.

Gelal A, Jacob P III, Yu L, and Benowitz NL (1999) Disposition kinetics and effects of menthol. Clin Pharmacol Ther 66:128-135.

Giovino GA, Sidney S, Gfroerer JC, O'Malley PM, Allen JA, Richter PA, and Cummings KM (2004) Epidemiology of menthol cigarette use. Nicotine Tob Res 6 (Suppl 1):S67-S81.

Green MD and Tephly TR (1996) Glucuronidation of amines and hydroxylated xenobiotics and endobiotics catalyzed by expressed human UGT1.4 protein. Drug Metab Dispos 24:356-363.

Gruber M, Le T, Filipits M, Gsur A, Mannhalter C, Jäger U, and Vanura K (2013) UDPglucuronosyltransferase 2B17 genotype and the risk of lung cancer among Austrian Caucasians. Cancer Epidemiol 37:625-628.

Haiman CA, Stram DO, Wilkens LR, Pike MC, Kolonel LN, Henderson BE, and Le Marchand L (2006) Ethnic and racial differences in the smoking-related risk of lung cancer. $N$ Engl J Med 354:333-342.

Hsu PC, Lan RS, Brasky TM, Marian C, Cheema AK, Ressom HW, Loffredo CA, Pickworth WB, and Shields PG (2017) Metabolomic profiles of current cigarette smokers. Mol Carcinog 56 594-606.

Ishii Y, Iida N, Miyauchi Y, Mackenzie PI, and Yamada H (2012) Inhibition of morphine glucuronidation in the liver microsomes of rats and humans by monoterpenoid alcohols. Biol Pharm Bull 35:1811-1817.

Jones MR, Tellez-Plaza M, and Navas-Acien A (2013) Smoking, menthol cigarettes and all-cause, cancer and cardiovascular mortality: evidence from the National Health and Nutrition Examination Survey (NHANES) and a meta-analysis. PLoS One 8:e77941.

Jones NR and Lazarus P (2014) UGT2B gene expression analysis in multiple tobacco carcinogentargeted tissues. Drug Metab Dispos 42:529-536.

Kabat GC and Hebert JR (1991) Use of mentholated cigarettes and lung cancer risk. Cancer Res 51:6510-6513.

Kaffenberger RM and Doyle MJ (1990) Determination of menthol and menthol glucuronide in human urine by gas chromatography using an enzyme-sensitive internal standard and flame ionization detection. J Chromatogr A 527:59-66.

Kozlovich S, Chen G, and Lazarus P (2015) Stereospecific metabolism of the tobacco-specific nitrosamine, NNAL. Chem Res Toxicol 28:2112-2119.
Kozlovich S, Chen G, Watson CJW, and Lazarus P (2019) Prominent stereoselectivity of NNAL glucuronidation in upper aerodigestive tract tissues. Chem Res Toxicol 32:1689-1698.

Kramlinger VM, von Weymarn LB, and Murphy SE (2012) Inhibition and inactivation of cytochrome P450 2A6 and cytochrome P450 $2 \mathrm{~A} 13$ by menthofuran, $\beta$-nicotyrine and menthol. Chem Biol Interact 197:87-92.

Lawrence D, Cadman B, and Hoffman AC (2011) Sensory properties of menthol and smoking topography. Tob Induc Dis 9 (Suppl 1):S3.

Lee PN (2011) Systematic review of the epidemiological evidence comparing lung cancer risk in smokers of mentholated and unmentholated cigarettes. BMC Pulm Med 11:18.

Munro HM, Tarone RE, Wang TJ, and Blot WJ (2016) Menthol and nonmenthol cigarette smoking: all-cause deaths, cardiovascular disease deaths, and other causes of death among blacks and whites. Circulation 133:1861-1866.

Murphy SE, Park SL, Balbo S, Haiman CA, Hatsukami DK, Patel Y, Peterson LA, Stepanov I Stram DO, Tretyakova N, et al. (2018a) Tobacco biomarkers and genetic/epigenetic analysis to investigate ethnic/racial differences in lung cancer risk among smokers. NPJ Precis Oncol 2:17.

Murphy SE, von Weymarn LB, Parenteau M, Stepanov I, Tiirikainen M, LeMarchand L, and Park SL (2018b) Influence of UGT2B 10 genotype on urinary excretion of 4-(methylnitrosamino)-1(3-pyridyl)-1-butanol- N-glucuronide by african American smokers. Chem Res Toxicol 31: $168-175$.

Murray RP, Connett JE, Skeans MA, and Tashkin DP (2007) Menthol cigarettes and health risks in Lung Health Study data. Nicotine Tob Res 9:101-107.

Muscat JE, Chen G, Knipe A, Stellman SD, Lazarus P, and Richie JP Jr (2009) Effects of mentho on tobacco smoke exposure, nicotine dependence, and NNAL glucuronidation. Cancer Epidemiol Biomarkers Prev 18:35-41.

Nemzek WR, Hecht S, Gandour-Edwards R, Donald P, and McKennan K (1998) Perineural spread of head and neck tumors: how accurate is MR imaging? AJNR Am J Neuroradiol 19:701-706.

Oertling H, Reckziegel A, Surburg H, and Bertram HJ (2007) Applications of menthol in synthetic chemistry. Chem Rev 107:2136-2164.

Park SL, Patel YM, Loo LWM, Mullen DJ, Offringa IA, Maunakea A, Stram DO, Siegmund K, Murphy SE, Tiirikainen M, et al. (2018) Association of internal smoking dose with blood DNA methylation in three racial/ethnic populations. Clin Epigenetics 10:110.

Pérez-Stable EJ, Herrera B, Jacob P III, and Benowitz NL (1998) Nicotine metabolism and intake in black and white smokers. JAMA 280:152-156.

Ren Q, Murphy SE, Zheng Z, and Lazarus P (2000) O-Glucuronidation of the lung carcinogen 4 (methylnitrosamino)-1-(3-pyridyl)-1-butanol (NNAL) by human UDP-glucuronosyltransferases 2B7 and 1A9. Drug Metab Dispos 28:1352-1360.

Rickert WS, Joza PJ, Sharifi M, Wu J, and Lauterbach JH (2008) Reductions in the tobacco specific nitrosamine (TSNA) content of tobaccos taken from commercial Canadian cigarettes and corresponding reductions in TSNA deliveries in mainstream smoke from such cigarettes. Regul Toxicol Pharmacol 51:306-310.

Rostron B (2012) Lung cancer mortality risk for U.S. menthol cigarette smokers. Nicotine Tob Res 14:1140-1144.

Saika K and Machii R (2012) Cancer mortality attributable to tobacco by region based on the WHO Global Report. Jpn J Clin Oncol 42:771-772.

Sidney S, Tekawa IS, Friedman GD, Sadler MC, and Tashkin DP (1995) Mentholated cigarette use and lung cancer. Arch Intern Med 155:727-732.

Signorello LB, Hargreaves MK, and Blot WJ (2010) The Southern Community Cohort Study: investigating health disparities. J Health Care Poor Underserved 21 (1 Suppl):26-37.

Stellman SD, Chen Y, Muscat JE, Djordjevic MV, Richie JP Jr, Lazarus P, Thompson S, Altorki N, Berwick M, Citron ML, et al. (2003) Lung cancer risk in white and black Americans. Ann Epidemiol 13:294-302.

Sun D, Chen G, Dellinger RW, Duncan K, Fang JL, and Lazarus P (2006) Characterization of tamoxifen and 4-hydroxytamoxifen glucuronidation by human UGT1A4 variants. Breast Cancer Res 8:R50.

Tobacco Products Scientific Advisory Committee (TPSAC) (2011) Menthol Cigarettes and Public health: Review of the Scientific Evidence and Recommendations.

Upadhyaya P, Kenney PM, Hochalter JB, Wang M, and Hecht SS (1999) Tumorigenicity and metabolism of 4-(methylnitrosamino)-1-(3-pyridyl)-1-butanol enantiomers and metabolites in the A/J mouse. Carcinogenesis 20:1577-1582.

United States Food and Drug Administration (2018) Drugs for human use (Editor: US Department of Health and Human Services).

Wassenaar CA, Conti DV, Das S, Chen P, Cook EH, Ratain MJ, Benowitz NL, and Tyndale RF (2015) UGT1A and UGT2B genetic variation alters nicotine and nitrosamine glucuronidation in european and african american smokers. Cancer Epidemiol Biomarkers Prev 24:94-104.

Wiener D, Doerge DR, Fang JL, Upadhyaya P, and Lazarus P (2004a) Characterization of $\mathrm{N}$-glucuronidation of the lung carcinogen 4-(methylnitrosamino)-1-(3-pyridyl)-1-butanol (NNAL) in human liver: importance of UDP-glucuronosyltransferase 1A4. Drug Metab Dispos 32:72-79. Wiener D, Fang JL, Dossett N, and Lazarus P (2004b) Correlation between UDPglucuronosyltransferase genotypes and 4-(methylnitrosamino)-1-(3-pyridyl)-1-butanone glucuronidation phenotype in human liver microsomes. Cancer Res 64:1190-1196.

World Health Organization (WHO) (2000) Obesity: preventing and managing the global epidemic. Report of a WHO consultation. World Health Organ Tech Rep Ser 894 (i-xii):1-253.

Xie SH, Rabbani S, Petrick JL, Cook MB, and Lagergren J (2017) Racial and ethnic disparities in the incidence of esophageal cancer in the United States, 1992-2013. Am J Epidemiol 186:1341-1351. Zheng Z, Fang JL, and Lazarus P (2002) Glucuronidation: an important mechanism for detoxification of benzo[a]pyrene metabolites in aerodigestive tract tissues. Drug Metab Dispos 30:397-403.

Address correspondence to: Dr. Philip Lazarus, Department of Pharmaceutical Sciences, College of Pharmacy and Pharmaceutical Sciences, Washington State University; 412 E. Spokane Falls Blvd, Spokane, WA 99210. E-mail: phil.lazarus@ wsu.edu 